ВЫБОР БАЗИСНОГО МАТЕРИАЛА ДЛЯ ПРОФИЛАКТИКИ ПОЛОМОК ПРОТЕЗОВ ПРИ ОРТОПЕДИЧЕСКОМ ЛЕЧЕНИИ БОЛЬНЫХ С ПОЛНЫМ ОТСУТСТСВИЕМ ЗУБОВ НА ВЕРХНЕЙ ЧЕЛЮСТИ ПРИ РАЗЛИЧНОЙ КОНФИГУРАЦИИ НЕБА

DOI: 10.31618/ESU.2413-9335.2019.3.69.491

Петросян А. Ф.

Лебеденко И. Ю.

(доктор медицинских наук, профессор, заслуженный деятель науки РФ)

ФГАОУ ВО РУДН, г. Москва

ФГАОУ ВО «Российский университет дружбы народов», Москва,

\title{
MATHEMATICAL MODELING OF STRESSES IN THE MULTI-THICKNESS BASIS OF REMOVABLE PLATE PROSTHESIS WITH PRONOUNCED TORUS OF THE UPPER JAW
}

\author{
A. F. Petrosyan ${ }^{1}$, I. Yu. Lebedenko ${ }^{2}$, \\ PEOPLES ' friendship University Of Russia, Moscow,
}

\begin{abstract}
АННОТАЦИЯ
Популярность традиционного съемного протезирования объясняется прежде всего экономичностью процедуры. Этот вариант протеза наиболее простой в изготовлении, что обусловливает его дешевизну и доступность.

Таким образом, съемные пластиночные протезы являются наиболее простым, доступным, а в некоторых случаях и единственным вариантом лечения для большинства беззубых пациентов. Наличие в полости рта торуса на верхней челюсти осложняют использование протезов, провоцируя болевые ощущения.

Протез в таких случаях упирается в торус, балансирует на нем, травмирует слизистую оболочку и соответственно в этом месте может переломиться базис протеза. В этом случае решением является изоляции в области торуса. В данном работе проводиться изучения минимально допустимых размеров толщины базисов съемных протезов в области небного торуса.

ABSTRACT

The popularity of traditional removable prosthetics is primarily due to the cost-effectiveness of the procedure. This version of the prosthesis is the easiest to manufacture, which causes its cheapness and availability.

Thus, removable plate prostheses are the easiest, most affordable, and in some cases the only treatment option for most toothless patients. The presence in the oral cavity of the torus on the upper jaw complicate the use of prostheses, provoking pain.

The prosthesis in such cases rests on the torus, balances on it, injures the mucous membrane and, accordingly, in this place, the basis of the prosthesis can be broken. in this case, the solution is isolation in the torus area. In this work, the study of the minimum allowable thickness of the bases of removable prostheses in the Palatine torus.

Ключевые слова: съемные протезы, базовые материалы, торус верхней челюсти, полная адентия, акриловые протезы, акриловые олигомеры, нейлоновые протезы, полиуретан.

Key words: Removable dentures, base materials, upper jaw torus, full adentia, acrylic dentures, acrylic oligomers, nylon prostheses, polyurethane.

\section{Введение.}

Современная ортопедическая стоматология располагает большим арсеналом базисных материалов различной химической природы для пластиночных зубных протезов. Их физикомеханические свойства соответствуют соответствующим требованиям, указанным в стандартах для базисных материалов. Однако, отсутствуют научно обоснованные подходы к выбору конкретного базисного материала (в

зависимости от его упруго-прочностных свойств) для конкретного клинического случая. Клинические данные свидетельствуют о большом разнообразии форм протезного ложа для съемного зубного протеза верхней челюсти - глубина нёба, выраженность торуса, степень податливости слизистой оболочки в различных зонах. Недоучёт этих факторов нередко приводит к поломкам базисов или неудовлетворительной фиксации протезов.
\end{abstract}




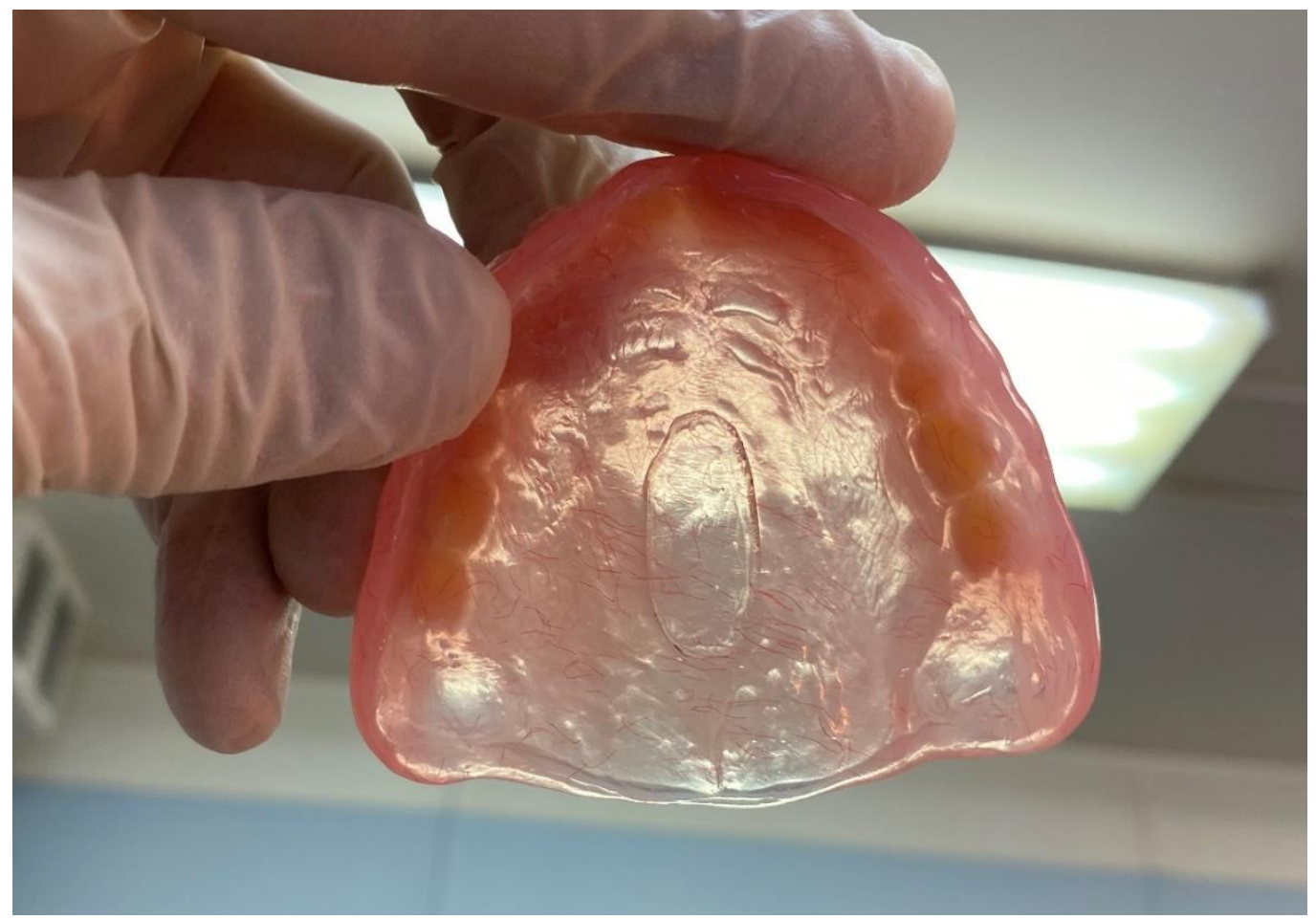

При изготовлении съемных пластиночных протезов при полном отсутствии зубов базисы протезов на верхней челюсти нередко изготавливают разнотолщинными с истончением в области срединного торуса для его изоляции.

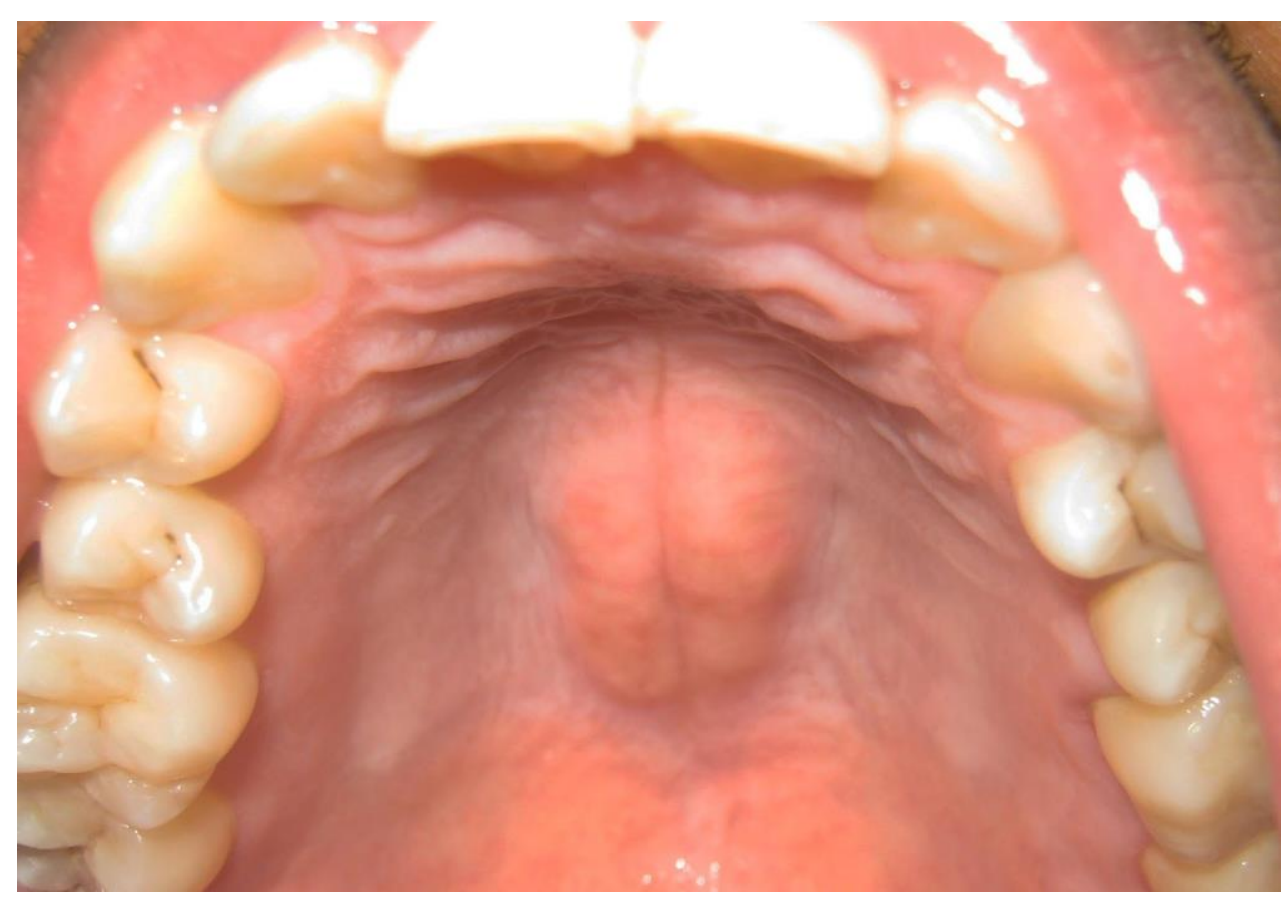

Описаны случаи резкой выраженности небного торуса - до 4 мм высотой. Известно, что там, где тонко, там и ломается. Однако в доступной нам литературе мы не встретили работ, посвященных научному обоснованию минимально допустимых размеров толщины базисов съемных протезов в области небного торуса.

\section{Цель работы.}

Методом конечных элементов исследовать напряженно-деформированное состояние базиса протеза в области торуса и рассчитать для отечественных полимерных базисных материалов минимально допустимые толщины протезов для предупреждения риска переломов при пороговых значениях жевательной нагрузки.

\section{Материалы и методы.}

Для достижения цели вначале в лаборатории материаловедения ФГБУ ЦНИИС и ЧЛХ МЗ РФ были определены основные физико-механические свойства 6 отечественных базисных материалов: «Пенталур» - на основе полиуретана; «Белакрил М ГО» - на основе метилметакрилата, горячей 
полимеризации; «Белакрил Э ГО» - на основе этилметакрилата, горячей полимеризации; «Белфлекс» - на основе полиамида для литьевого формования; «Эвихард» - на основе нейлона для литьевого формования; светоотверждаемый материал «Нолатек» - на основе акриловых олигомеров.

\begin{tabular}{|c|c|c|c|c|}
\hline $\begin{array}{c}\text { № } \\
\text { п/п }\end{array}$ & $\begin{array}{c}\text { Наименование (марка) } \\
\text { базисного материала }\end{array}$ & $\begin{array}{c}\text { Предел прочности } \\
\text { при изгибе МПа }\end{array}$ & $\begin{array}{c}\text { Модуль упругости } \\
\text { при изгибе, МПа }\end{array}$ & $\begin{array}{c}\text { Деформация при } \\
\text { изгибе, \% }\end{array}$ \\
\hline 1 & Белакрил-М ГО & $95 \pm 9,3$ & $2417 \pm 135$ & $6,1 \pm 1,5$ \\
\hline 2 & Белакрил-Э ГО & $86,3 \pm 8,5$ & $2144 \pm 91$ & $2,9 \pm 1,4$ \\
\hline 3 & Нолатек & $41,6 \pm 3,3$ & $2043 \pm 96$ & \\
\hline 4 & Пенталур & $95,5 \pm 1,1$ & & $6,7 \pm 0,03$ \\
\hline 5 & Эвихард & $51,4 \pm 2,6$ & $2049 \pm 187$ & $8,4 \pm 0,6$ \\
\hline
\end{tabular}

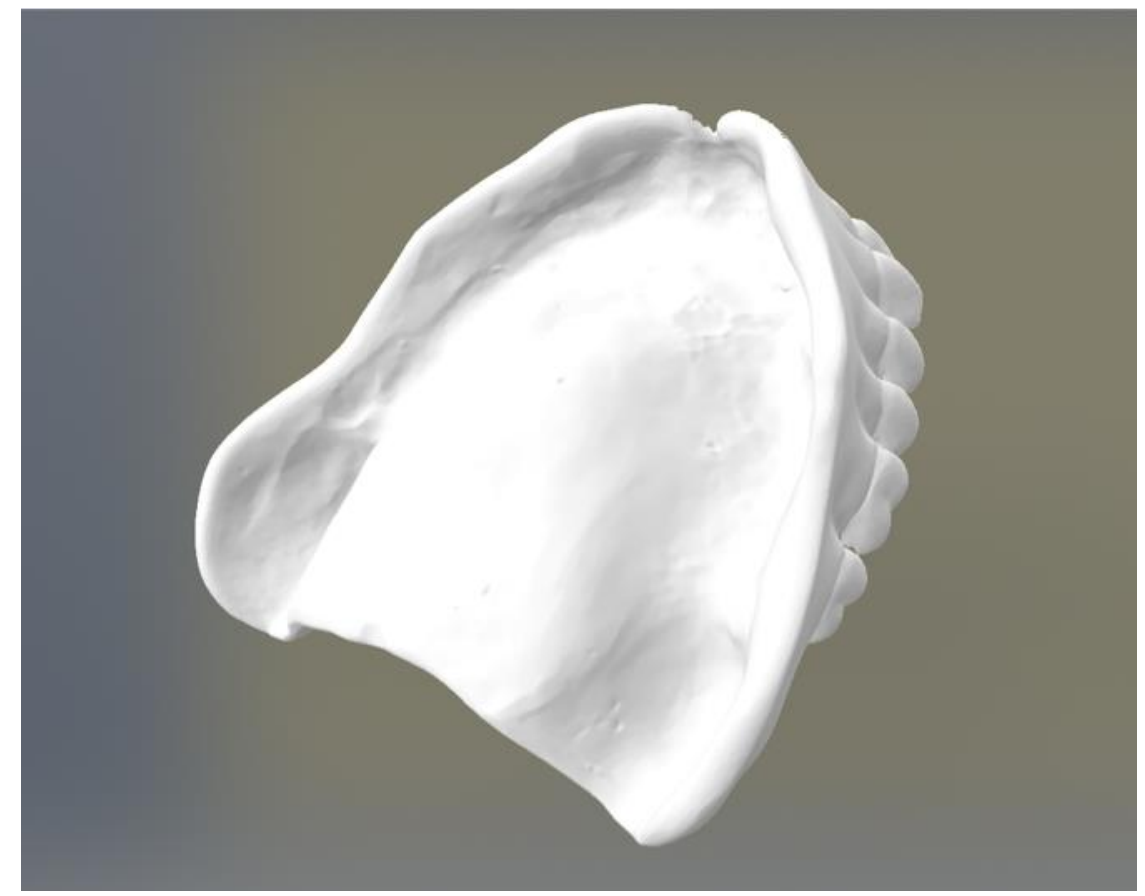

Для построения математической модели съемного пластиночного протеза на беззубой верхней челюсти с помощью лабораторного сканера Zfx Evolution PRO получили скан реальной гипсовой модели с верхнечелюстным торусом высотой 1,9 мм и скан реального протеза. 


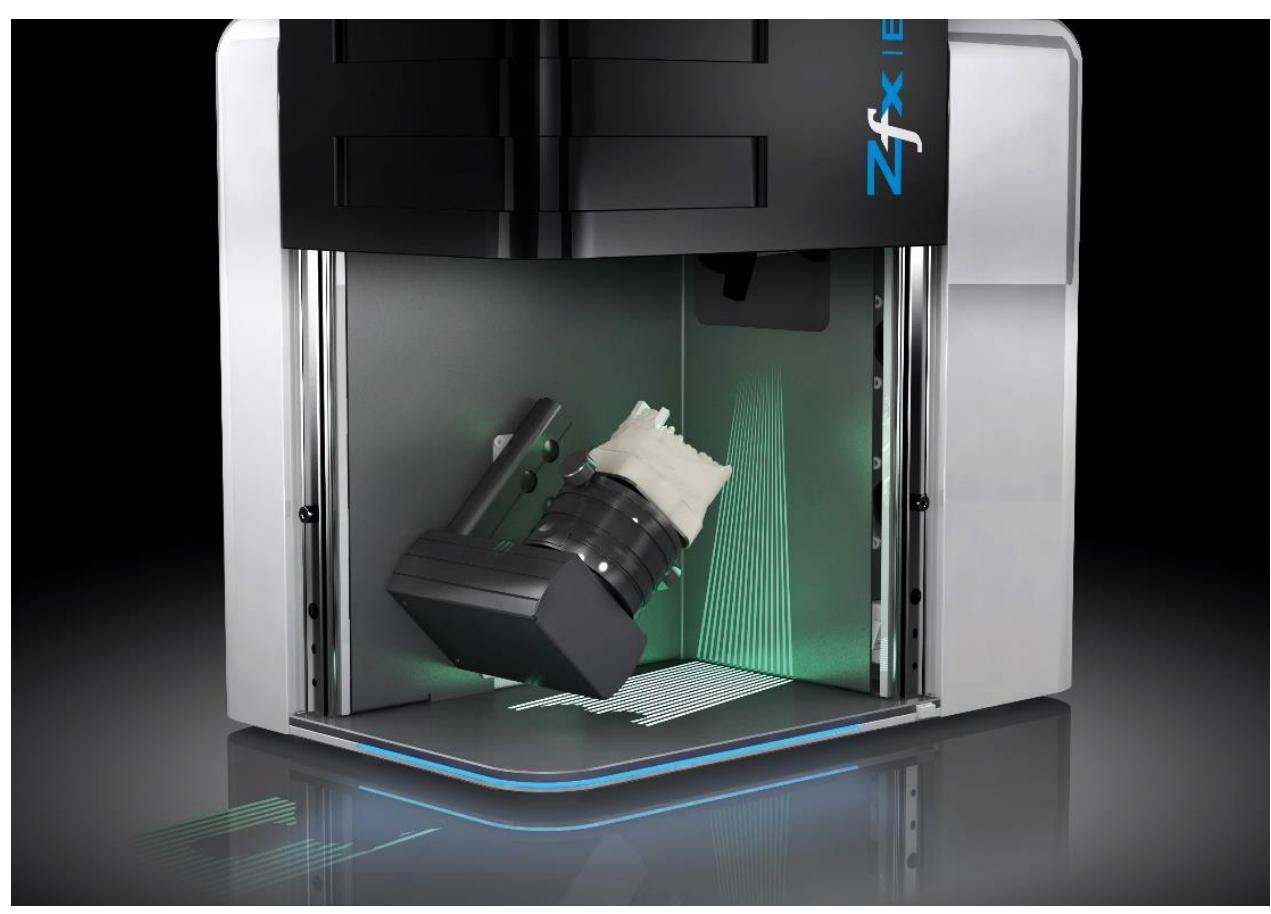

Для аггравации ситуации увеличили высоту торуса на модели до 4 мм с применением математического аппарата программы ABAGUS совместили вышеуказанные сканы в единой

виртуальной модели. Распределенную жевательную нагрузку в 50 Н прикладывали с обеих или с одной стороны зубного ряда.

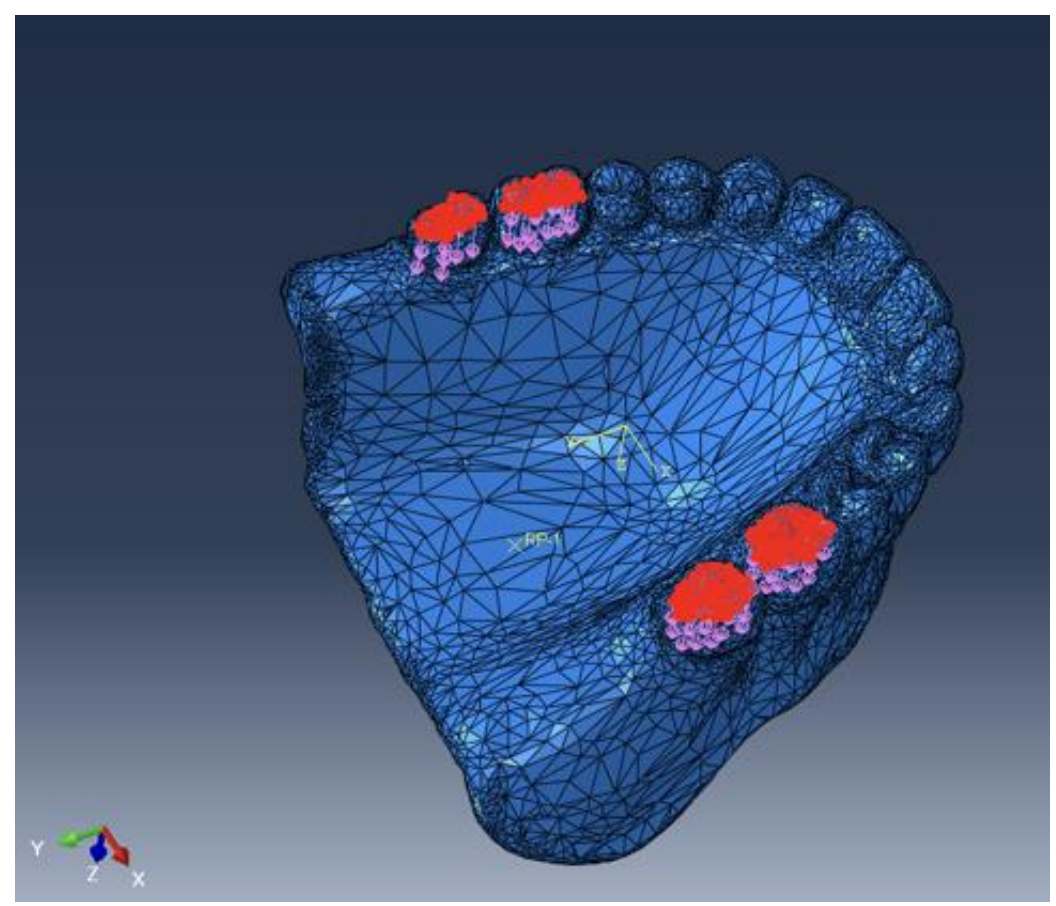

Чтобы задать граничные условия вводили определенные в лаборатории параметры базисных материалов: предел прочности при изгибе и модуль эластичности при изгибе 6 используемых в Российской Федерации базисных стоматологических материалов отечественного производства. Суть исследования состояла в определении напряжений, возникающих при изменении толщины базиса над торусом, моделируя принятую в зубопротезировании его изоляцию, и сравнения уровня возникающих в базисе напряжений с пределом прочности материала на изгиб. Находили для каждого материала толщину базиса в области изоляции, при которой предел прочности пластмассы при изгибе совпадал с величиной упругих напряжений в базисе. 


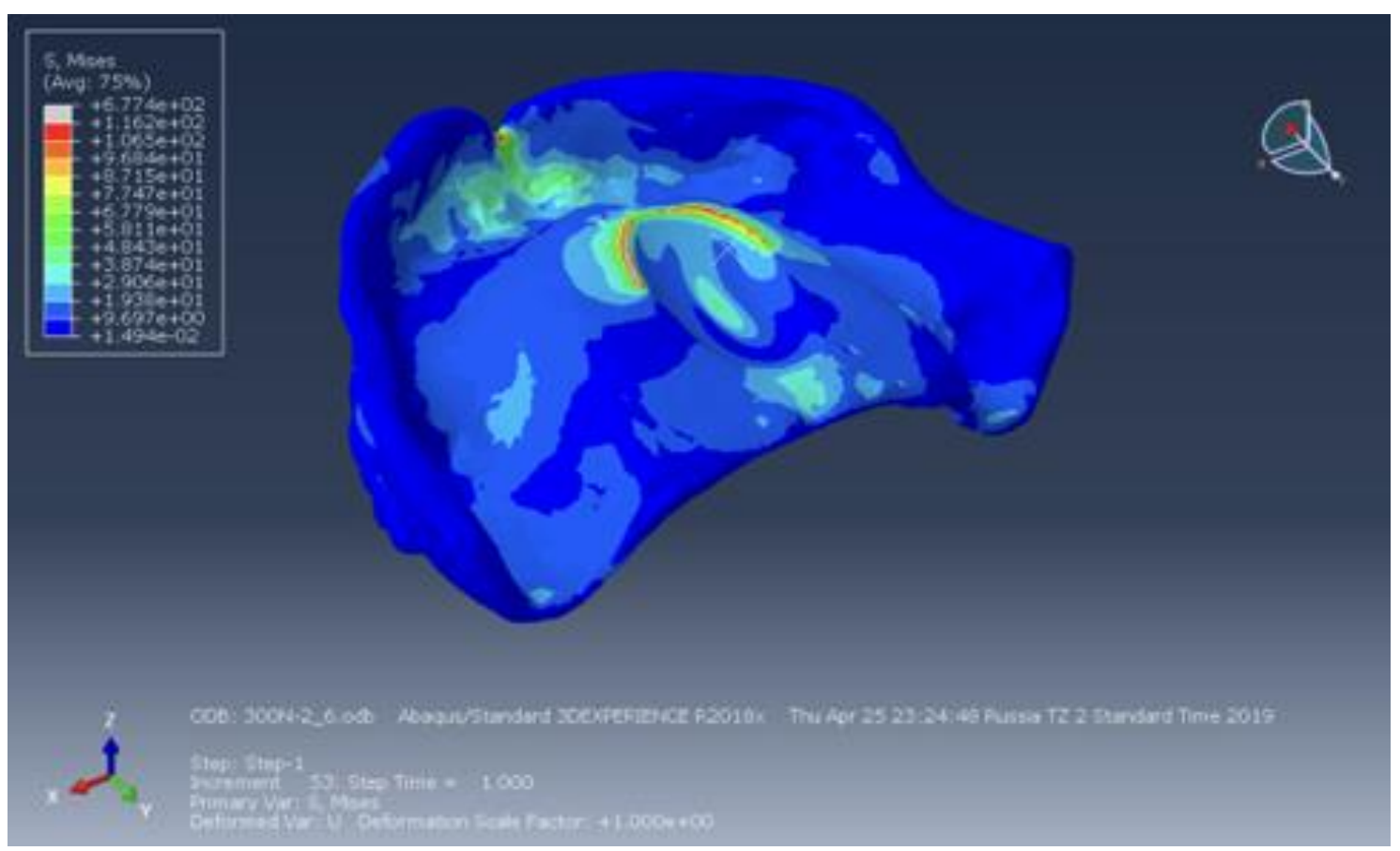

На слайде представлены картины напряжений, возникающих в разных зонах базиса полного протеза при его нагружении. Отчетливо видны ярко красные области максимальных напряжений. Мы определяли напряжения, возникающие при изменении толщины базиса над торусом, моделируя принятую в зубопротезировании его изоляцию и сравнивали уровень возникающих в базисе напряжений с пределом прочности материала на изгиб.

\section{Результаты.}

Мы установили, что самую высокую прочность при изгибе имеют образцы из материала «Пенталур»- 95,5 МПа, а самую низкую «Нолатек» - 41,6 МПа. Самый высокий показатель модуля эластичности - у материала «Белакрил М ГО»- 2417 МПа, самый низкий - у материала «Белфлекс» - 1270 МПа.

Проведенные нами расчеты показали, что минимальные допустимые толщины базисов съемных пластиночных зубных протезов в зоне истончения для изоляции небного торуса возможны в случае применения акриловой пластмассы «Белакрил М ГО» и полиуретана «Пенталур» и составляют 2,3 мм. Очень близкое значение минимально допустимой толщины у акриловой пластмассы «Белакрил Э ГО» - 2,4 мм. У полиамидов толщина должна быть больше: «Белфлекс» - 2,7 мм и «Эвихард» - 3,1 мм. Для светоотверждаемого базисного материала «Нолатек», толщина в зоне изоляции торуса должна быть не менее 3,5 мм, что практически неприемлемо.

В настоящий момент мы проводим клиническую апробацию предложенного метода профилактики переломов базисов полных съемных протезов при выраженном торусе. При соблюдении предложенных размерных параметров у нас не наблюдалось ни одного случая перелома базиса протеза. Срок наблюдения небольшой - до 2-х лет.

\section{Выводы.}

1.Научно обоснованной минимально допустимой толщиной базиса съемного пластиночного протеза для верхней беззубой челюсти при резко выраженном торусе является величина 2.3 мм для изученных отечественных базисных пластмасс.

2.Отечественный базисный материал «Нолатек» не следует применять у пациентов с беззубой верхней челюстью и резко выраженным торусом.

\section{Библиографический список.}

1.Гаврилов Е.И. Протез и протезное ложе. М.: Медицина, 1979. -263 с.

2.Василенко А.О., Ченцов Е.П. Особенности клинико-лабораторных этапов изготовления полных съемных пластиночных протезов // Организация, профилактика и новые технологии в стоматологии: Материалы 5 съезда стоматологов Беларуси. - Брест, 2004. - G.302-303. 3

3.Воронов И.А., Воронов А.П., Лебеденко И.Ю. Ортопедическое лечение больных с полным отсутствием зубов. М.: МЕДпресс-информ, 2006. $320 \mathrm{c}$.

4.Brauer H. Изготовление полных съемных протезов у лиц преклонного возраста. Стратегия успеха // Квинтессенция. 1997. - №5/6. - С. 2731.

5.Marxkors R. Полные съемные протезы // Новое в стоматологии. -2004. № 7. - С. 36-49.

6.Y.Y. Chenga,*, J.Y. Lib, S.L. Fokb, W.L. Cheungc, T.W. Chowa, 3D FEA of high-performance polyethylene fiber reinforced maxillary dentures, Dental materials 26 (2010) e211-e219.

\section{Literature.}

Gavrilov E. I. Prosthesis and prosthetic bed. Moscow: Medicine, 1979. -263 PP.

Vasilenko A. O., Chentsov E. P. Features of clinical and laboratory stages of manufacturing 
complete removable plate prostheses / / Organization, prevention and new technologies in dentistry: Materials of the 5 th Congress of dentists of Belarus. - Brest, 2004. - G. 302-303. Three

Voronov I. A., Voronov A. P., Lebedenko I. Yu. Orthopedic treatment of patients with complete absence of teeth. Moscow: Medpress-inform, 2006. - 320c.

Brauer H. Production of complete dentures in the elderly. Strategy success / / Quintessence. 1997. - No. 5/6. - Pp. 2731.

Marxkors R. Complete dentures / / New in dentistry. -2004. No. 7. - Pp. 36-49.

Y. Y. Chenga, M., J. Y. Lib, S. L. Fokb, W. L. Cheungc, T. W. Chowa, 3D FEA of high-performance polyethylene fiber reinforced maxillary dentures, Dental materials 26 (2010) e211-e219.

Сведения об авторах:

Петросян Артур Феликсович - врачстоматолог-ортопед ГАУЗ «Пушкинская городская стоматологическая поликлиника», врачстоматолог-ортопед ООО «АртДент».

Ответственный автор, контактная информация:

ФГАОУ ВО «Российский университет дружбы народов», Москва. Тел.: +7(929)539-2222. e-mail:

Лебеденко Игорь Юльевич - заслуженый деятель науки РФ, «Отличник здравоохранения», доктор медицинских наук, заведующий лабораторией разработки и физико-химических испытаний стоматологических материалов ЦНИИС и ЧЛХ, заведующий кафедрой ортопедической стоматологии медицинского факультета РУДН, Член совета директоров Ассоциации цифровой стоматологии, редактор журнала «Цифровая стоматология», автор более 50 научных работ по стоматологической тематике.

\title{
ВЛИЯНИЕ ЭПИДУРАЛЬНОЙ АНАЛГЕЗИИ НА ФУНКЦИОНАЛЬНЫЕ ПОКАЗАТЕЛИ ПРИ ИНТРААБДОМИНАЛЬНОЙ ГИПЕРТЕНЗИИ.
}

Пидмурняк $\boldsymbol{A} . \boldsymbol{A}$.

Д.мед.н.

Хмельницькая областная больница, г. Хмельнициий, Украина.

\begin{abstract}
АННОТАЦИЯ
Вступление: синдром интраабдоминальной гипертензии и его сочетание с органной дисфункцией (абдоминальный компартмент синдром) осложняют течение хирургических заболеваний брюшной полости. Если определение степени интраабдоминальной гипертензии является рутинной практикой, то определение абдоминального перфузионного давления заинтересовало исследователей сравнительно недавно. Тем не менее снжение перфузии органов брюшной полости, в частности почек является одной из причин последующей полиорганной недостаточности, приводящей к смерти пациента. Целью работы было определение влияния эпидуральной аналгезии на динамику интраабдоминального и абдоминального перфузионного давления, и клинические показатели у пациентов с острой хирургической патологией, осложненной развитием синдрома интраабдоминальной гипертензии.

Методы: обследовано 60 послеоперационных пациентов с острой хирургической патологией органов брюшной полости и признаками внутрибрюшной гипертензии. Первую группу пациентов $(\mathrm{n}=30)$ составили пациенты стандартной опиоидной аналгезии, вторую $(\mathrm{n}=30)$ пациенты, которым проводили эпидуральную аналгезию болюсным введеним 1\% раствора лидокаина. Всем пациентам проводили измерение давления в мочевом пузыре каждые 6 часов по общепринятой методике, после каждого измерения рассчитывали абдоминальное перфузионное давление.

Результаты: в результате работы установлено, что при использовании перидуральной аналгезии определяются периоды достоверного снижения интраабдоминального и достоверного увеличения абдоминального перфузионного давления.

Выводы: использование эпидуральной аналгезии имеет определённые преимущества в предотвращении прогрессирования интраабдоминальной гипертензии и эффективно корригирует абдоминальное перфузионное давление.

Ключевые слова: интраабдоминальная гипертензия, абдоминальный компартмент - синдром, абдоминальное перфузионное давление.

Условные сокращения: ИАД - интраабдоминальное давление, АПТ - абдоминальное перфузионное давление.

Вступление. Повышение внутрибрюшного давления выше 10 мм рт ст. в течение $1-2$ суток приводит к летальным последствиям в $3-7 \%$ случав, а при повышении этой величины до 35 мм рт ст. в течение $6-7$ часов указывает на $100 \%$ летальность. Абдоминальный компартмент синдром определяют как стойкое повышение

внутрибрюшного давления до уровня выше 20 мм рт ст., которое ассоциировано с манифестацией органной недостаточности. Абдоминальный компартмент не требует классификации по степени гипертензии, поскольку представлен феноменом «всё или ничего», в отличие от синдрома интраабдоминальной гипертензии, который
\end{abstract}

